\title{
How do patients perceive ambulatory psychiatric care and what are their needs?
}

\author{
Aleksandra Małus', Beata Galińska-Skok'1, Beata Konarzewska', Agata Szulc ${ }^{1}$ \\ ${ }^{1}$ Department of Psychiatry, Medical University, Bialystok, Poland
}

Małus A, Galińska-Skok B, Konarzewska B, Szulc A. How do patients perceive ambulatory psychiatric care and what are their needs? Ann Agric Environ Med. 2018; 25(1): 90-94. doi: 10.5604/12321966.1233559

\begin{abstract}
Introduction and objective. The quality of a doctor-patient relationship plays a vital role in all fields of medicine. In the case of psychiatry, this role is special as it provides the foundation for the whole therapeutic process. The aim of this study was to investigate the patient's perspective on psychiatric visits: patient's attitudes towards the psychiatrist, patient's view of the patient-psychiatrist relationship, and the patient's needs and expectations from this relationship.

Materials and method. 615 psychiatric outpatients responded to the anonymous questionnaires connected with their attitudes towards the psychiatrist, evaluation of the doctor, and expectations from psychiatric care. The study was conducted in 10 out of 30 public centres for psychiatric care in north-eastern Poland.

Results. Generally, the patients liked and positively evaluated their psychiatrists. Patient's liking for the doctor was connected with the feeling that the doctor also liked the patient, as well as with perceiving the doctor as competent and willing to meet the patient. The longer the treatment with a particular psychiatrist and the rarer need to consult the doctor, the more positive attitude and evaluation of the doctor patients had. According to the patients, the most significant expectations were associated with both conversation with the doctor and receiving emotional support.

Conclusions. The key phase for forming the patient-psychiatrist relationship was the first stage of cooperation in which patients created their attitudes towards the doctor without modifying them at further stages. Thus, further studies on learning and developing the ability to establish the relationship with the patient, inspiring the patient's trust and making psychiatric appointments comfortable from the first meeting, will be highly valuable.
\end{abstract}

Key words

physician-patient relation, patient-centred care, psychiatry

\section{INTRODUCTION}

The patient-centred approach is a widespread and preferred way of a patient-clinician interaction in medical care [1]. Focusing on the patient during medical encounters is especially important in psychiatric care as the mental state of the patient (negative symptoms, anxiety, low mood) may particularly influence the interaction [2]. The therapeutic process may be difficult and demanding, not only due to the type of symptoms of a mental disorder, but also because of the duration of the symptoms. The chronic nature of many conditions and mental diseases, as well as the relapse of low mood following relatively stable periods, discourage patients from the treatment [3]. According to the research, compliance in chronic diseases is considerably lower compared to shortlasting diseases [4] and, according to the WHO, amounts to $50 \%$ [5]. It has been shown that successful management of chronic illnesses depends on the active behavioural involvement of the patient [6]. However, the attempt to involve patients into the therapeutic process should not include persuading them to comply with the doctor's recommendations [7]. According to the rules, patient-centred care should have the character of a cooperation based on (1) eliciting and understanding the patient's perspective-concerns, ideas, expectations, needs, feelings, and functioning [2], understanding the patient within his or her unique psychosocial context [3], reaching

Address for correspondence:Aleksandra Małus, Department of Psychiatry, Medical University of Blalystok, Poland

E-mail:aleksandrawalukmalus@gmail.com

Received: 9 February 2014; accepted: 9 February 2015; first published on February 2017 a shared understanding of the problem and its treatment with the patient that is in accordance with the patient's values [4)], creating a partnership in which the patients can share in decision-making, power, and responsibility [8]. Patient involvement in the treatment according to the rules of patientcentredness requires the doctor's familiarity with the patient's expectations, needs and feelings towards the psychiatrist [9].

\section{OBJECTIVES}

The aim of this study was to investigate the patient's perspective in psychiatric visits: patient's attitude towards the psychiatrist, patient's view of the patient-psychiatrist relationship, and patient's needs and expectations connected with this relationship. It was assumed that a better familiarity with patients' perspectives in the process of a psychiatric ambulatory treatment would help to learn the patient's views, and thus introduce changes within doctors' actions that would make the psychiatric care more patient-centred.

\section{MATERIALS AND METHOD}

The study included psychiatric adult outpatients treated in a public mental health care facility, irrespective of the diagnosis. All the individuals had reported to a psychiatrist more than once.

The patients evaluated their attitudes towards the psychiatrist with the use of a four-item scale Attitude towards the doctor (Cronbach's $\alpha=0.82$ ). The statements referred to 
emotional, cognitive and behavioural spheres (1=strongly disagree to $5=$ strongly agree). These items had been used in the previous research on patients' attitude towards the psychiatrist [10]. In the case of this research, a question about the patient's subjective feeling about the doctor's attitude: I think this doctor likes me, was added [11]. Total score range: 4-20.

Patients described the psychiatrist's behaviour on 12 items (1=strongly disagree to $5=$ strongly agree). The statements formed by the authors was aimed at the optimal reflection of such aspects of the psychiatrist-patient relationship as: communication, information, decision sharing, support, respect, friendly openness. Five questions were taken from the EUROPEP 2006-SF 10 [12], and one from the research by Roter et al. [13]. These 12 items formed a reliable scale with Cronbach's $\alpha=0.82$. Total sore range: $12-60$.

Evaluation of patients' expectations was performed with the use of the Patient Request Form $[14,15,16]$. The scale included 18 statements, 6 for each of the 3 factors: explanation and reassurance, emotional support, investigation and treatment. Each item was rated on a 3-point scale (agree $=2$, uncertain $=1$, disagree $=0$ ). The Cronbach's $\alpha$ for PRF in this study was 0.93 . Total score range: $0-36$.

The study was conducted in 10 out of 30 randomly-selected public centres for mental health care in north-eastern Poland. At the point of making the appointment with a psychiatrist, the patients were given a questionnaire at the reception and asked to fill it in before the consultation. The questionnaire was anonymous, voluntary and free of charge. The patient could fill it in or not, and put into a box in the reception.

The correlations between liking variables were calculated with Spearman's rho. The relationship between the main variables (patient's attitude towards the doctor, patient's evaluation of the doctor, and patient's expectations) were shown with Pearson correlations. The differences between the subgroups, including socio-demographic variables, were analysed with the $t$ Student test. In the case of analysing complex relations the MANOVA was used.

\section{RESULTS}

Out of 1,000 spread questionnaires, 615 were returned. Analysis was carried out on 338 female and 277 male patients aged between 18-82 (mean=46.33; SD =12.88). 145 patients had higher education, 255 secondary education, 139 vocational and 76 primary education.

419 individuals lived in urban and 195 in rural areas. 380 of the studied persons had been in a professional relationship with a doctor for many years, 159 persons had known their doctor for approximately a year, while 76 patients had been in contact with the doctor less than a year.

Most commonly, the patients consulted the psychiatrist once in a few months $(\mathrm{N}=292)$ or once a month $(\mathrm{N}=262)$. A small group of patients made appointments once a week $(\mathrm{N}=5)$ or once a fortnight $(\mathrm{N}=56) .457$ questionnaires completed by the patients referred to a female doctor while 158 to a male doctor.

Generally, the patients showed a positive attitude towards their psychiatrists (mean=17.7; $\mathrm{SD}=2.38$ ). I like this doctor. (mean=4.58; $\mathrm{SD}=0.66)$, I think this doctor likes me. $($ mean $=4.06 ; \mathrm{SD}=0.84)$, I think this doctor is competent (mean=4.59; $\mathrm{SD}=0.68)$, I willingly meet with this doctor (mean=4.47; $\mathrm{SD}=0.79$ ). Patient's liking for the doctor was related to the following factors: considering the doctor a competent person ( $r h o=0.69 ; \mathrm{p}<0,001)$, willingness to meet with the doctor $(r h o=0.68 ; \mathrm{p}<0,001)$, and the feeling that the doctor also liked the patient ( $\mathrm{rho}=0.49 ; \mathrm{p}<0,001)$.

No difference between the attitude towards the psychiatrist between male and female patients was found. Additional analyses were performed in order to determine whether the same or opposite gender of patient and the doctor was related to liking for the doctor, competence rating and patient's needs to consult the doctor. No such relations were observed. Similarly, no relation between patient's age/ place of living and the attitude towards the psychiatrist was found. A statistically significant relation between patient's attitude towards the doctor and the length of therapy with a particular doctor was observed $(\mathrm{F}=21.69 \mathrm{p}<0,001)$. This relation was also connected with particular components of the attitude: I like this doctor. $(\mathrm{F}=18.32 \mathrm{p}<0,001)$, I think this doctor likes me. $(\mathrm{F}=13.83 \mathrm{p}<0,001)$, I think this doctor is competent. $(\mathrm{F}=11.63 \mathrm{p}<0,001)$, I willingly meet with this doctor. $(\mathrm{F}=12.49 \mathrm{p}<0,001)$. The patients who remained under the care of a particular doctor for a longer time showed a more positive attitude towards the doctor, liked him/her and felt more liked, considered him/her as more competent and sought the contact with him/her. Multiple comparison analyses showed the dynamics of patient's attitude towards the doctor. A key factor in the formation of patient's attitude towards the psychiatrist was the first stage of therapy, from a week to a year $(\mathrm{F}=1.59 \mathrm{p}<0,001)$. Therapeutic relation underwent no significant changes on further stages of the treatment. Patient's attitude towards the doctor was significantly related with the frequency of consultations $(F=8.16 p<0,001)$. The most positive attitude towards the psychiatrist was observed in persons who made appointments the least often.

The psychiatric care was evaluated by patients as follows: mean $=48.45 ; \mathrm{SD}=0.66$. Communication competence of the doctor had higher ratings (answers my questions mean $=4.64$; $\mathrm{SD}=0.58$ and listens to me carefully, mean=4.60; $\mathrm{SD}=0.61$ ). Mean ratings of particular aspects of doctors' behaviour towards the patients are presented in Figure 1.

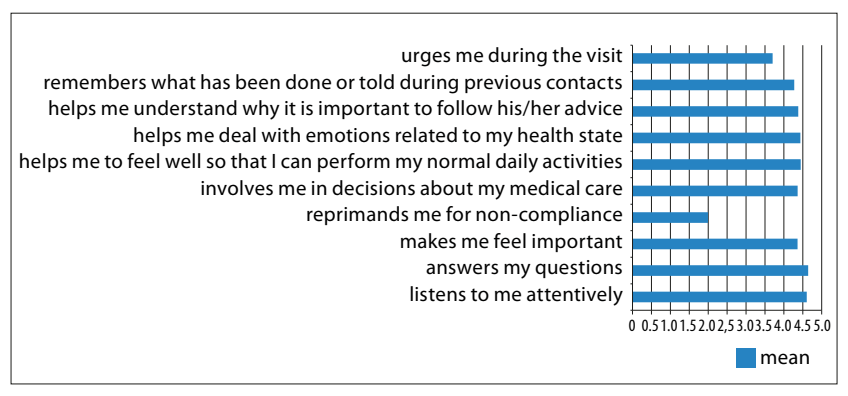

Figure 1. Mean ratings of particular aspects of doctor's behavior towards the patients

No statistically significant differences were observed between psychiatrist evaluation by male and female patients, nor by persons of different ages. The patients remaining under the longer care of a particular doctor evaluated their help more positively $(\mathrm{F}=9.93 ; \mathrm{p}<0,001)$. Also, the patients who consulted the doctor more rarely evaluated doctor's help more positively $(\mathrm{F}=7.63 ; \mathrm{p}<0,001)$. Similar to the patients' attitude towards the doctor, also in the case of patients' evaluation of the doctor, the key role was played by the first period of 
contact $(\mathrm{F}=2.99 ; \mathrm{p}<0,001)$ during which the evaluation was basically formed and remained unchanged at further stages.

Patient's expectations from the psychiatrist reached the mean level $=26.44 ; \mathrm{SD}=8.56$ (Fig. 2). The most common expectations were those from the explanation and reassurance group (mean=9.42; $\mathrm{SD}=3.19$ ) and from the emotional support group (mean $=9.39 ; \mathrm{SD}=3.25)$. The least common expectations were those strictly related with the treatment - investigation and treatment (mean $=7.64 ; \mathrm{SD}=2.99$. The difference between particular groups of expectations was significant $(\mathrm{F}=236.28$; $\mathrm{p}<0,001)$. No statistical difference was found between expectations of male and female patients. Also, no relation was observed between the type and number of expectations reported by patients and the same or opposite gender of the patient and the doctor. Moreover, no dependency between a patient's age and place of residence and their expectations from the doctor. No relation was noted between therapy duration, frequency of visits and expectations from the doctor.

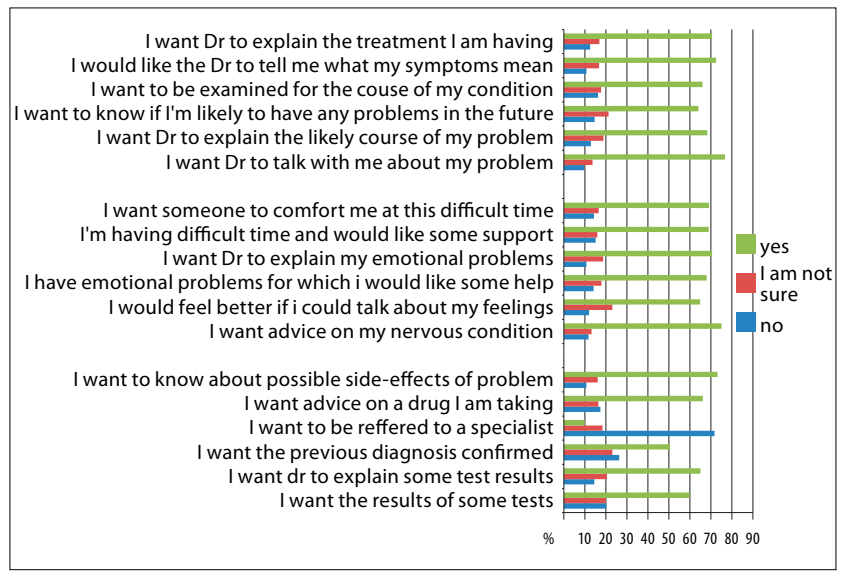

Figure 2. Patients' expectations from the psychiatrist (Patient Request Form)

A significant relationship between patients' attitudes towards the psychiatrist, patients' evaluation of the psychiatrist and patients' expectations from the psychiatrist was observed. A positive attitude of patients towards the psychiatrist was connected with the patients' positive evaluation of the psychiatrist $(\mathrm{r}=0.73 ; \mathrm{p}<0,001)$, as well as a great number of expectations from the psychiatrist $(r=0.16$; $\mathrm{p}<0,001)$. Also, a positive psychiatrist evaluation by the patients was related to higher expectations from the doctor $(\mathrm{r}=0.18 ; \mathrm{p}<0,001)$.

\section{DISCUSSION}

Patients showed a positive attitude and positive feelings towards the psychiatrist. The formation of a patient's attitude towards a doctor was in accordance with the general rules of human attitudes. Primacy effect involves the impact of the first received information on subsequent information, and may explain both the first impression and quick formation of an opinion about the newly-met person [17]. According to the results of the presented study, the patients formed their attitudes towards the psychiatrist at the first stage of the therapy and consequently held to these attitudes which, typically, were positive. It is possible that the patients who evaluated the psychiatrist negatively during the first consultations resigned from the therapy, or changed either the facility or the doctor. This was confirmed by a study of the drop-outs which indicated a big percentage of treatment discontinuations at the first stage of therapy [18].

Another rule, the mere exposure effect, indicates that due to an increasing frequency of contact with the subjects, the attitude towards them changes affectively [19]. The patients remaining in contact with a psychiatrist longer, and thus having a greater number of consultations, evaluated the doctor more positively and presented a more positive attitude towards that psychiatrist. However, a more positive attitude towards the doctor was shown by the individuals who consulted the psychiatrist more rarely. This dependency may result from the fact that the frequency of psychiatric consultations depends on the patient's state of health.

According to clinical practice, unstable patients, persons in the acute phase of the disease and in a bad mental state, are recommended more frequent consultations with the psychiatrist. Patients in remission are offered follow-ups once a month or once every few months. The patients who were stable and treated effectively showed a greater satisfaction with the contact with the psychiatrist, and presented a more positive attitude towards the psychiatrist. The relation between satisfaction with treatment and liking for the doctor has also been observed in other studies [20]. The fact that the analysed treatment was a psychiatric therapy is probably also of vital importance. Although the stereotypes related to mental disorders and psychiatric treatment have weakened, a number of people still associate psychiatric therapy with stigmatization, which causes resistance [21]. In this context, patients who need fewer psychiatric consultations may feel relieved and satisfied due to the limited necessity to confront the stereotype, which is confirmed by the research in social psychology on the stereotype threat [22].

A patient's attitude towards the psychiatrist was formed regardless of the gender, which has been confirmed by other studies [23]. No relationship was observed between the same or opposite gender of the patient, and doctor and patient's attitude towards the psychiatrist. According to other studies, the level of liking for the doctor was similar in same-gender and opposite gender pairings, yet a greater patients' (men and women) liking for female doctors [11] and female doctors' liking for patients (women and men) were also observed [24]. Nor was any relationship observed between patient's attitude towards the doctor and patient's age, education and place of ressidence. The results of other studies connected with the relations between socio-demographic variables and the attitude towards the doctor are discrepant [25].

The evaluation of the doctor from the aspect of received psychiatric care shows that psychiatrists display a repertoire of behaviours that can be called 'patient-centred'. Psychiatrists' communication competence was rated particularly positively. The behaviour of the evaluated doctors included the focus on patients' needs, involving patients in the decision- making process and explaining the recommendations. It seems that in Poland, as well as in other countries, the patient-centred attitude in the clinical setting has increased [26], which is confirmed by studies on the quality of psychiatric service in Poland [27]. Numerous patients had the impression of being urged pressurised prompted during the visit. The Polish Ministry of Health has issued a regulation on psychiatric treatment which established that a psychiatric consultation ought to last at least 45 minutes in the case of diagnostic 
appointments (initial interview, establishing the problems, making psychiatric diagnosis), at least 30 minutes in the case of therapeutic meetings (treatment change, modification of recommendations), and at least 15 minutes in the case of follow-ups (continuation of current treatment). The current study did not concern first-time patients, and therefore most of the consultations lasted 15 - 30 minutes. A 15-minute consultation once every few months may leave the patient dissatisfied. Regardless of the appointment duration, patients may have their own subjective impression that they were not devoted enough time by the doctor. However, quality research on the course of doctor-patient contact shows that both patient's satisfaction and therapeutic effects depend not on the consult duration, but on the quality of the contact (voice tone, showing kindness) [28].

According to the results of the crrent study, the longer the treatment with a particular psychiatrist and the rarer need to meet him/her, the more positive the attitude and evaluation the patients had of the doctor. Concurrently, patients formed their attitudes towards the psychiatrist during the first contacts with the, without changing it at further stages of the therapy. These observations showed both the special significance of the first psychiatrist-patient contact and the special need of establishing the relationship with patients, with full attentiveness to their needs. Analysis of patients' expectations from the first psychiatric consultation conducted by Pribe et al. showed that patients gave the most positive ratings to psychiatrists who shared the information about what will happen in the consultation, rather than those with briefer introductions or with additional personal disclosure [29]. Further quality studies in this field are necessary.

Patient's expectations from the psychiatrists referred first of all to the need to talk about the problems experienced by the patients and to receiving emotional support, which confirms the demand for the therapeutic aspects of this relationship. The many expectations of the surveyed patients confirm that they reported to a psychiatrist as they intentionally and consciously sought advice about their mental health.

The study was of a 'one-off' nature, in which participation was anonymous, voluntary and free of charge. However, there was the risk that the patients who were strongly dissatisfied with the psychiatric care, or with increased severity of disease symptoms, were unwilling to cooperate with the facility and refused to complete the questionnaires. However, a different way of constructing the study could violate the anonymity of the studied patients, which the researchers attempted to avoid. The questionnaires included no diagnosis variable, although certain reports suggest that the type of disorder may impact on both patient's attitude in the doctor-patient relationship, and the expectations from the treatment. The question of the type of diagnosis was considered by the authors to be inappropriate in an anonymous questionnaire.

\section{CONCLUSIONS}

Although the study included the connection between the length of the doctor-patient relationship, it provides no foundation for formulating cause and effect conclusions. An issue that is interesting and inspiring for future research is how patients' attitudes towards the psychiatrist develop with the change of the factors related with the disease and its treatment.
According to the study, the quality of a doctor-patient relation plays a vital role in all fields of medicine [30]. In case of psychiatry, this role is special as it gives the foundation for the whole therapeutic process.

The great majority of the patients positively evaluated their psychiatrists, liked them evaluated them as competent, and met them willingly. The key phase for creating the patientpsychiatrist relationship was the first stage of contact and the relation formed at that point did not change significantly at further stages of the therapy.

It is impossible to recommend psychiatrists to like all their patients as it depends on numerous psychological variables upon which they have no impact. However, it is vital that doctors make every attempt to reflect the feelings they experience toward patients during routine visits, especially first consultations, as liking in a patient-psychiatrist relationship translates into a positive evaluation of the received psychiatric care. Psychiatrists should be attentive to the needs of their patients, among which the most significant are connected with emotional support. Most crucial for patients is that they are listened to, find understanding and receive moral support. Patients are sensitive to the fact whether or not the doctor pays attention and takes an interest in them. Therefore, psychiatrists should make every effort to create an atmosphere of calm, kindness, and attentiveness during consultations, despite time limitations, and provided the necessary services.

\section{Acknowledgement}

The study was supported by Grant No. 124-47542 L from the Ministry of Science and Higher Education in Warsaw, Poland.

\section{REFERENCES}

1. Smith RC, Fortin AH, Dwamena F, Frankel RM. An evidence-based patient-centered method makes the biopsychosocial model scientific. Patient Educ Couns. 2013; 91: 265-70.

2. McCabe R, Khanom H, Bailey P, Priebe S. Shared decision-making in ongoing outpatient psychiatric treatment. Patient Educ Couns. 2013; 91: $326-8$.

3. Oehl M, Hummer M, Fleischhacker WW. Compliance with antipsychotic treatment. Acta Psychiatr Scan. 2000; 102(407): 83-6.

4. Sluijs E, Dulmen S, Djik L, Ridder D, Heerdink R, Bensing J. Patient adherence to medical treatment: a meta review. Utrecht, Nivel, 2006.

5. World Health Organization. Adherence to long-term therapies. Evidence for action. Geneva, WHO, 2003.

6. Michi S, Miles J, Weinman J. Patient-centeredness in chronic illness: what is it and does it matter? Patient Educ Couns. 2003; 51: 197-206.

7. Entwistle VA, Renfrew MJ, Yearley S, Lamont JF. Lay perspectives: Advantages for health research. Brit Med J. 1998; 319: 463-6.

8. Mead N, Bower P. Patient-centeredness: A conceptual framework and review of the empirical literature. Soc Sci Med. 2000; 51: 1087-110.

9. Thomson S, Doody G. Parallel paths? Patient and doctor priorities in psychiatric outpatient consultations. J Mant Health. 2010; 19(5): 461-9.

10. Małus A, Galińska-Skok B, Hykiel R, Szulc A. The meaning of physician-patient relation for neuroleptic treatment. Arch Psychiatr Psychother. 2011; 4: 21-8.

11. Hall JA, Horgan TG, Stein TS, Roter DL. Liking in the physician-patient relationship. Patient Educ Couns. 2002; 48: 69-77.

12. Wensing M. Revised Europep instrument and user manual. UMC St Radboud, 2006

13. Roter DL, Hall JA, Kern DE, Barker LR, Cole KA, Roca RP. Improving physicians' interviewing skills and reducing patient' emotional distress: a randomized clinical trial. Arch Int Med. 1995; 155: 1877-84.

14. Salmon P, Quine J. Patients' intentions in primary care: measurement and preliminary investigation. Psychol Health. 1989; 3(2): 103-10. 
15. Valori R, Woloshynowych M, Bellenger N, Aluvihare V, Salmon P. The Patient Request Form: a way of measuring what patients want from their general practitioner. J Psychosom Res. 1996; 40(1): 87-94.

16. Juczyński Z. Narzędzia pomiaru w promocji i psychologii zdrowia. (Measurement tools in health psychology and promotion.) Warszawa: Pracownia Testów Psychologicznych, 2009; 143-8.

17. Shteingart H, Neiman T, Loewenstein Y. The role of first impression in operant learning. J Experiment Psychol. 2013; 142(2): 476-88.

18. Shamir D, Szor H, Melamed Y. Dropout, early termination and detachment from a public psychiatric clinic. Psychiatr Danub. 2010; 22(1): 46-50.

19. Zajonc R. Attitudinal effects of mere exposure. J Personal Social Psychol. 1968; 9(2): 1-27.

20. Hall JA, Milburn M, Roter D, Daltroy L. Why are sicker patients less satisfied with their care? Health Psychol. 1998; 17: 70-5.

21. Świtaj P, Wciórka J, Grygiel P, Anczewska M, Schaeffer E, Tyczyński $\mathrm{K}$, Wiśniewski A. Experiences of stigma and discrimination among users of mental health services in Poland. Transcult Psychiatry. 2012; 49(1): 51-68.

22. Steele C, Aronson J, Stereotype threat and the intellectual test performance of African American. J Personal Social Psychol. 1994; 69(5): 797-811.
23. Hall JA, Epstein AM, DeCiantis M, McNeil BJ. Physicians' liking for the patients: further evidence for the role of affect in medical care. Health Psychol. 1993; 12: 140-6.

24. Hall JA, Dornan MC. Patient sociodemographic characteristics as predictors of satisfaction with medical care: a meta-analysis. Soc Sci Med. 1990; 30: 811-8.

25. Roter DL, Hall JA. Doctors talking with patients/Patients talking with doctors. Westport, Connecticut London, 2006.

26. Finset A., Person centered healthcare - Do we see any progress? Patient Educ Couns. 2008; 72: 174-5.

27. Janczewska M, Raduj J, Induska A, Pałyska M, Prot K. Patients' opinions on services provided in psychiatric and neurological wards - a comparison. Psychiatr Pol. 2010; 44(2): 255-65.

28. Cruz M, Roter DL, Cruz RF, Wieland M, Larson S, Cooper LA, Pincus HA. Appointment length, psychiatrists' communication behaviors, and medication management appointment adherence. Psychiatr Serv. 2013; 64(9): 886-92.

29. Pribe S, Palumbo C, Ahmed S, Strappelli S, Gavrilovic JJ, Bremner S. How psychiatrists should introduce themselves in the first consultation: an experimental study. Br J Psychiatr. 2013; 202: 459-62.

30. Levinson W, Frankel RM, Roter D, Drum M. How much do surgeons like their patients? Patient Educ Couns. 2006; 61: 429-34. 